Herança - Revista de História, Património e Cultura

\title{
PURO PENITENTE
}

A SNLVACIOO NÃO VEN DE GRACA

Pure Penitent - Salvation does not come from Grace

\section{Marco António Fontes de Sá}

E-mail: maf.sa@terra.com.br

Pontifícia Universidade Católica de São Paulo 


\section{Resumo}

Este artigo pretende apresentar e discutir a origem e a ação religiosa dos grupos de Penitentes da região do Cariri Cearense, particularmente da cidade de Barbalha, que fica a cerca de 11 km de Juazeiro do Norte, e sua relação com o poder público, com a Igreja e com a comunidade. Ele se baseia em pesquisas já realizadas sobre o tema, acrescentando a própria experiência do autor, que acompanhou as procissões e orações, durante o período da Semana Santa em 2018 e entrevistou pessoas do clero e leigos, além dos próprios Penitentes e Incelências.

Palavras-chave: penitentes; cariri; religiosidade popular; sacrifício.

\section{Abstract}

This article intends to present and discuss the origin and religious action of the Penitentes groups of the region of Cariri Cearense, particularly of the city of Barbalha, which is about $11 \mathrm{~km}$ from Juazeiro do Norte, and its relation with the public power, with the Church and with the community. It is based on research already done on the subject, adding the author's own experience, which accompanied the processions and prayers, during the Holy Week period in 2018 and interviewed people of the clergy and laity, as well as Penitents themselves and Injunctions themselves.

Keywords: penance; cariri; popular religiosity; sacrifice. 


\section{O Cariri Cearense}

Cariri é uma região do Brasil que abrange os estados do Ceará, Paraíba, Pernambuco, Alagoas, Sergipe e Bahia. Era o nome genérico de várias tribos de nativos que habitavam essa região.

Barbalha é uma cidade do Cariri Cearense, a cerca de 10 quilômetros de Juazeiro do Norte e 20 quilômetros de Crato.

Barbalha, Crato e Juazeiro do Norte, formam um triângulo que, como várias outras regiões do Cariri, tem uma história intimamente ligada ao catolicismo popular temperado com devoções peculiares, milagres não oficialmente reconhecidos, apagamento da memória e, consequentemente, resistência.

É nessa região que aparece e existe até hoje a Ordem dos Penitentes. Um grupo de homens católicos, eventualmente acompanhados de mulheres (as Incelências), cujo objetivo básico é sofrer. Um tipo de espiritualidade que, por diversos fatores, se ajusta às condições de vida da população carente de um sistema de crença que ajude a suportar a seca, a fome, a pobreza brutal e a falta de oportunidades em todos os setores.

As Incelências e os Penitentes são manifestações peculiares de uma religiosidade popular gerada num estado com uma história peculiar, onde o sofrimento e a força de vontade sempre andaram lado a lado.

\section{O servo sofredor - Sofrimento e sacrifício como forma de redenção.}

O Cristianismo surgiu no primeiro século de nossa era como um conjunto de pessoas que se propunham a viver o judaísmo de uma forma diferente, baseada na solidariedade e sobretudo no perdão, cujo símbolo máximo foi o sacrifício voluntário de seu líder que se tornou "o cordeiro de Deus que tira os pecados do mundo", numa alusão aos sacrifícios de reconciliação com Deus, realizados no templo de Jerusalém. 
Transformado na versão Católico-Romana, esse Cristianismo se tornou a religião hegemônica de toda a Europa durante a maior parte da Idade Média e cresceu baseada no poder e na autoridade do clero e das suas relações com o poder secular.

O Catolicismo se expandiu e estruturou sua prática com base nos Sacramentos $^{1}$ que no início eram, principalmente, o Batismo, a Comunhão e a Confissão. Todos com a função de purificar e santificar quem os recebia. A Confissão, também chamada de Penitência tem, entre suas várias origens a peregrinação ${ }^{2}$ que monges irlandeses, na baixa idade média, faziam como forma de reparação dos pecados. Eles saiam sem destino, contando apenas com a providência divina e com a solidariedade das pessoas, para ter o que comer e beber e onde dormir, se sujeitando à fome e ao frio e, portanto, ao sofrimento. (ROUILLARD, p.47-48)

O clero retinha (e ainda retém) a posse desses sacramentos e o poder de determinar que os podia receber. Consequentemente era quem determinava quem podia ser perdoado de suas faltas.

No final do século XIII a Igreja era uma instituição poderosa, inclusive politicamente. É quando o Concílio de Latrão define o sistema de sete sacramentos e quando surgem as congregações de frades mendicantes, os Franciscanos e os Dominicanos, que serão muito rapidamente absorvidas pela hierarquia da Igreja, numa estratégia de manutenção do controle sobre tudo aquilo que dizia respeito à religião. Na virada do século XV par o XVI surge na Europa o movimento humanista que pretendia com novas propostas de difusão do conhecimento e de reestruturação das universidades que surgiram no período medieval. Uma vertente desse movimento, ligada ao Cristianismo, se desenvolveu no norte da Europa tendo Erasmo de Rotterdam como um dos seus principais articuladores. Sua obra, "Elogio da Loucura", escrita na primeira década do século XVI, criticava a ganância e imoralidade do clero da Igreja Católica. Esse pensamento será absorvido por Martin Lutero e desencadeará o princípio da Reforma Protestante.

\footnotetext{
1 O uso de letra maiúscula tem a ver com o respeito pelo significado da palavra Sacramento e ao nome dos Sacramentos: Batismo, Confissão e Comunhão.
} 
A Igreja Católica respondeu com outro movimento chamado de Contrarreforma e como o Concílio de Trento (1545-1563) afirmando sua autoridade, a validade de seus dogmas e buscando retomar o controle da religião em toda a Europa. A Contrarreforma, também chamada de romanização, chegará ao Brasil muito lentamente, na medida em que a colonização avançava, alicerçada primeiramente no plantio da cana de açúcar, que se espalhou com força na região nordeste.

\section{Padre Ibiapina, Padre Cícero, e a colonização do Ceará}

O nordeste brasileiro foi o grande polo da produção de canade-açúcar, o "ouro verde", escolhido como o recurso que viabilizaria o início da colonização. Entretanto, os grandes latifúndios e a produção agrícola (fosse ela de cana-de-açúcar ou posteriormente de algodão), voltada para a exportação, impediam uma agricultura de subsistência, o que fazia com que os pequenos agricultores se tornassem totalmente dependentes dos latifundiários, que lhes concediam onde morar e o que comer. Entre os séculos XVIII e XIX esse latifundiário terá o sugestivo nome de "coronel".

Nesse cenário é que surgem as figuras do Pe. Ibiapina e posteriormente, do Pe. Cícero, que, com uma atuação semelhante, mas não igual à dos coronéis, acolhia a população mais pobre.

No Ceará a inexistência de metais preciosos, a falta de chuvas e a resistência das tribos nativas, desestimulavam a colonização que ficou a cargo de padres missionários franciscanos e jesuítas que tinham como meta a busca da santidade através da penitência e do sofrimento, e que exercitavam uma pregação baseada na eterna luta entre Deus e o Diabo. Ibiapina sucedeu esses missionários, mas seu projeto era revolucionário.

Ibiapina será o iniciador de um movimento de protagonismo laico que terá sequência no Pe. Cícero e que também foi o modelo das comunidades seguidoras de beatos como Antonio Conselheiro e José Lourenço (Canudos e Caldeirão). 
Como consequência, enfrentará a resistência do processo de romanização da Igreja que, apesar de ter surgido no Concílio de Trento (1545-1563) só vai chegar por aqui nos meados do século XVIII.

Figura emblemática, Pe. Ibiapina foi ordenado sacerdote aos 47 anos, depois de uma carreira como advogado, juiz, chefe de polícia e deputado federal pelo Ceará. Dedicou-se a uma vida de ajuda ao próximo e de oração e se tornou um padre missionário, responsável pela organização de mutirões populares para a construção de açudes, cemitérios, escolas e as Casas de Caridade, algumas das quais se tornarão hospitais, não só no Ceará mas também na Paraíba, Rio Grande do Norte e Pernambuco, e que suprirão as necessidades dos pobres, não atendidas pelo Estado. Essas instituições serão administradas por leigas e leigos convocados por Ibiapina, e que se dedicarão exclusivamente a essas funções.

Segundo Anna Christina Farias de Carvalho, há referências à presença dos Penitentes em Barbalha antes de 1850 e, portanto, antes da chegada de Ibiapina, e pode ter sido consequência de uma prática que já existia na Europa entre os séculos XIII e XV. (CARVALHO, 2011, p.27-28).

Todavia é possivel que tenha sido incentivada pelas ações missionárias que Ibiapina realizou no chamado Cariri novo (Missão Velha, Crato, Barbalha, Milagres, Porteira) no ano de 1868. Para os Penitentes, entretanto, Ibiapina é o iniciador e legitimador do movimento.

\section{Um manual de penitência - A Missão Abreviada}

Na segunda metade do século XIX, um livro publicado em Portugal pelo padre Manoel José Gonçalves Couto (18191897) tornou-se um manual da vida missionária no Ceará. A Missão Abreviada tinha, já na primeira página, um resumo do seu objetivo: "Para despertar os descuidados, converter os pecadores, e sustentar os frutos das missões". 


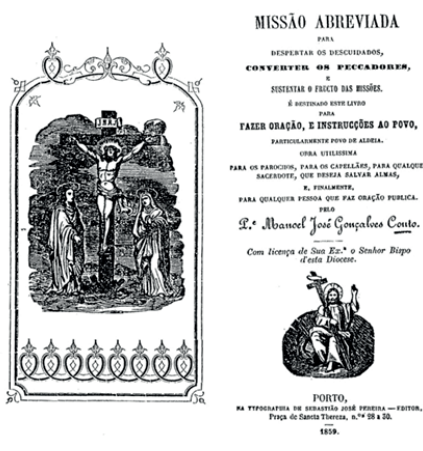

Primeira página de um exemplar da Missão Abreviada

\section{Um manual de penitência - A Missão Abreviada}

Na segunda metade do século XIX, um livro publicado em Portugal pelo padre Manoel José Gonçalves Couto (18191897) tornou-se um manual da vida missionária no Ceará. A Missão Abreviada ${ }^{3}$ tinha, já na primeira página, um resumo do seu objetivo: "Para despertar os descuidados, converter os pecadores, e sustentar os frutos das missões".

Anna Christina Farias de Carvalho transformou sua pesquisa de doutorado sobre os Penitentes do Cariri cearense num livro chamado: Sob o signo da fé e da mística.

A autora acompanhou e entrevistou membros de alguns grupos de Penitentes em Juazeiro do Norte e em Barbalha nos anos de 1988 e 1989 e depois em 2002 e afirma ter visto um exemplar da Missão Abreviada nas mãos de um dos Decuriões 4 .

O texto da Missão Abreviada é totalmente comprometido com a busca da santidade pelo sacrifício e penitência.

Destaco aqui um trecho onde esse apelo fica evidente:

Portanto se te queres salvar, peccador, deixa já o peccado e cuida em fazer rigorosa penitencia; eu digo rigorosa penitencia, sobre o que deves considerar no que diz Santo Ignacio: «A sentença está dada contra ti, peccador; na verdade estás condemnado ao inferno, porque cahiste no peccado; e por mais que tenhas feito, não sabes se já está revogada a tua sentença de condemnação eterna; estes dias que o Senhor te concede, são dias de salvação; não é tempo de rir, nem de zombar; não é tempo de prazeres ou vaidades; ó sim tempo de chorar e de gemer; é tempo de clamar a Deos perdão c misericórdia; é tempo de fazer penitencia, fugindo aos louvores, aos divertimentos e aos regalos, e procurando desprezos, abatimentos e mortificações;

3

Informações não confirmadas oficialmente afirmam que foi o livro mais editado em Portugal no século XIX, com mais de 16 edições e 140 mil exemplares.

4

Decurião é o líder do grupo de penitentes e responsável por iniciar o canto do Benditos. Falaremos sobre isso adiante. Nas conversas que eu tive com os Decuriões atuais um deles mencionou um livro, que pode ser um exemplar da Missão Abreviada, que foi roubado por um jornalista há alguns anos. 
ainda que já tenhas feito vinte ou trinta annos de penitencia (diz o Santo) não descanses, não cesses, faz ainda mais penitencia, porque não sabes se já estás perdoado... (Missão Abreviada Sec. XIX - p. 102)

Lendo esse trecho do livro torna-se possível imaginar como a autoflagelação vai fazer parte do cotidiano dos Penitentes.

Para os leitores da Missão Abreviada, o perdão não vem apenas pela graça, consequência do arrependimento, mas de um processo de sofrimento que, em resumo, é o castigo pelas faltas, que precisa ser ministrado antes do perdão.

Num cenário onde o povo já era sofredor em consequência da seca frequente e da falta de recursos, a autoflagelação pode ter aparecido como uma maneira de se destacar nesse sofrimento.

\section{O caminho asfaltado dos Penitentes de hoje.}

Os Penitentes e as Incelências (grupo feminino) de Barbalha entendem como missão a visita aos cemitérios e aos cruzeiros ${ }^{5}$ nas beiras de estradas, especialmente na Páscoa e no dia de finados. Fazem também as exéquias de alguns falecidos, sempre rezando o terço e cantando os Benditos, ${ }^{6}$ cujas letras trazem adaptações das histórias das escrituras, da vida dos santos misturadas com a dos falecidos (nas exéquias) e com tradições e parábolas populares e cuja memorização é parte do orgulho dos mestres, conhecidos como Decuriões.

As Incelências, e é esse o nome com que fazem questão de serem chamadas, são em geral esposas ou parentes dos Penitentes. 5

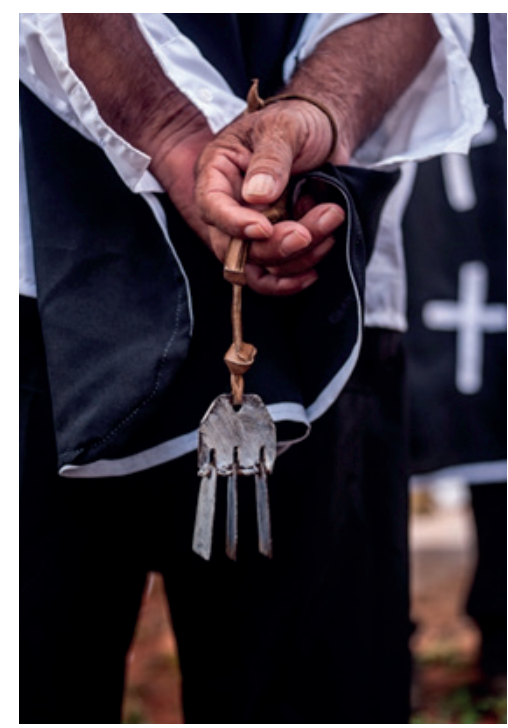

Disciplina 


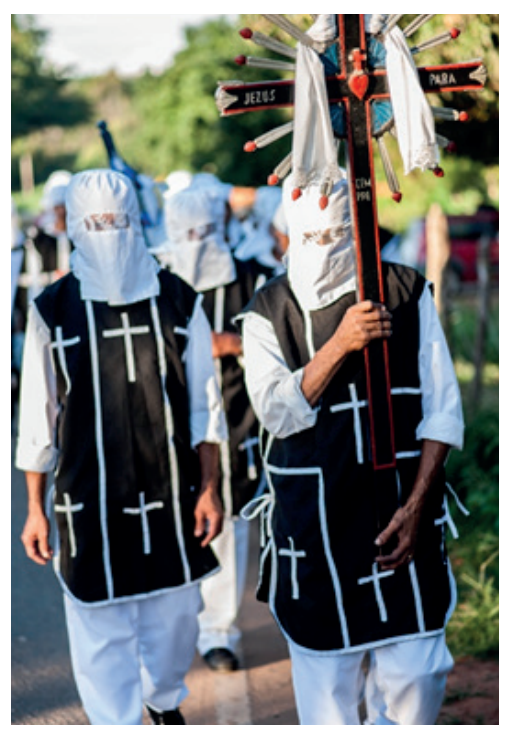

Penitentes
Há 3 grupos de Penitentes em Barbalha. Todos vestem roupas pretas, mas há alguns grupos de outras cidades que usam o vermelho e o azul escuro. Todos os componentes, exceto o Decurião têm o rosto coberto por um véu. A explicação para isso é que assim o Penitente não pode ser reconhecido se tiver uma conduta não exemplar, que é indispensável para que ele participe do grupo. A despeito de professarem uma fé distante do clero, os penitentes não admitem, por exemplo, homens que vivem amasiados. Assim, apesar de prescindirem do contato frequente com um padre, eles respeitam e desejam os sacramentos. Entretanto, o uso do véu cobrindo o rosto não pretende apenas prevenir que um membro do grupo seja acusado de ser pecador, mas também evitar que aquele que acusa faça um julgamento e que por isso, consequentemente, também peque.

A autoflagelação, prática comum há cerca de 20 anos e exclusiva dos Penitentes, ${ }^{7}$ não é mais realizada, ou pelo menos é isso que os membros com quem conversei dizem publicamente. Mesmo assim, muitos ainda carregam consigo a "disciplina", ${ }^{8}$ por ser ela uma parte de sua indumentária tradicional.

Em alguns de seus Benditos, a dor da disciplina ainda é lembrada:

Ai Jesus!

Que grande dor

A dor da disciplina que trespassou

Cortando a disciplina, o corpo do Penitente

O povo diz que não dói,

O nosso corpo é que sente

Apesar de se considerarem católicos, os Penitentes materializam sua devoção longe das igrejas e raramente entram em uma delas.

Num primeiro momento, imaginei que isso fosse consequência de divergências tão comuns entre o clero e a "religiosidade profana" que existe nos Penitentes, mas pesquisando e observando um pouco mais, entendi que não é bem assim. 
O "carisma" dos Penitentes é realmente estar fora das igrejas e eles até nelas entram quando estão vazias. Em seu livro, Sob o signo da fé e da mística, Anna Christina Farias de Carvalho menciona uma Missa laica, e pela descrição que ela faz dessa celebração, que seria justamente o momento em que entram nas igrejas para rezar diante do Santíssimo Sacramento, sem a presença oficial de um padre, eu suponho que tive a oportunidade de acompanhar um desses momentos ou algo bem semelhante a ele.

A conversa com o pároco da cidade esclareceu como ele vê essa separação. Ele chegou na cidade havia apenas dois meses, pouco tempo, portanto, para fazer um juízo da situação. Mas confirmou que há, de fato, uma certa prevenção contra as manifestações populares. Todavia ela não está diretamente ligada aos Penitentes e sim a alguns excessos que acontecem na maior festa da cidade, que é a de Santo Antonio, conhecida como festa do pau da bandeira de Santo Antonio.

O receio em relação aos Penitentes é, de fato, um respingo do que existe em relação à festa do pau da bandeira.

Registrada pelo IPHAN como patrimônio imaterial em 2015, a festa foi, em 2017, o tema do I Simpósio Patrimônio e Práticas Culturais: a Festa de Santo Antônio de Barbalha, do qual tive a oportunidade de participar como ouvinte.

Nesse simpósio, representantes do IPHAN, dos carregadores do mastro (pau da bandeira), do clero e do poder público apresentaram suas preocupações e sugestões em relação aos problemas e desafios que estão surgindo, na medida em que a festa começa a ser cada vez mais conhecida e frequentada. Encontros com os mestres dos grupos de Congo e de outras manifestações populares também foram organizados.

Como acontece com frequência com a cultura e com a religiosidade popular, quando ela chama tanto a atenção que o poder público assume sua manutenção, lucros e prejuízos são igualmente agregados à sua existência. O poder público contribui para sua manutenção da mesma forma que para sua transformação em espetáculo que, em geral, retira dela a essência, o mistério e a devoção. 


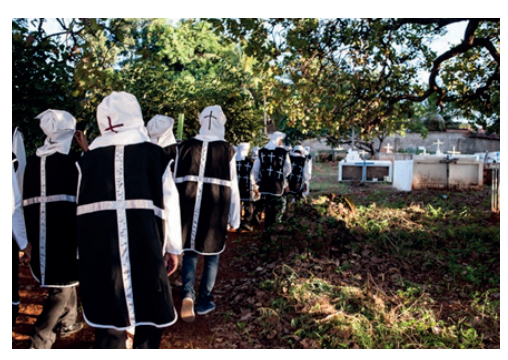

Penitentes em visita ao cemitério
Nesses novos caminhos asfaltados, por onde os Penitentes transitam hoje, muita coisa mudou e vem mudando, desde que os primeiros se autoflagelaram nos cemitérios da região. Agora eles são convidados a participar da festa do pau da bandeira (Santo Antonio) e de uma procissão do fogaréu entre as duas igrejas da cidade, durante a Semana Santa.

Anna Christina Farias de Carvalho já havia, em sua pesquisa de 1998, registrado o desconforto dos Penitentes em participar da festa de Santo Antonio e, de fato, essa participação que nada mais é do que uma apresentação, é incoerente com a mítica fundadora da missão dos Penitentes, que está estritamente ligada às celebrações da Páscoa e do dia de finados. Quanto à procissão do fogaréu, ela já existia em outra comunidade cearense $^{9}$ (Várzea Alegre) mas não existia em Barbalha, onde foi criada há menos de 10 anos, por integrantes da Secretaria Municipal de Cultura e encampada pelo governo do estado.

Mas a cultura popular tem como forma de resistência, justamente sua capacidade de adaptação sem perder a essência. Tempos novos podem exigir novas estratégias que nem sempre conseguem ser implantadas sem ajuda.

Andar à noite pela estrada de Arajara para visitar cruzeiros e cemitérios não é uma tarefa fácil para homens com mais de 70 anos. Para fazer isso é bom que os Penitentes contem com o apoio de batedores com luzes de advertência que ajudam os motoristas dos carros que transitam na estrada a perceberem o que está acontecendo. Também é bom contar com um transporte para levar o grupo a outras cidades. Quando assegura esse "conforto", o poder publico acolhe e patrocina a cultura popular sem intervir prejudicialmente na sua existência. Todavia, quando estabelece roteiros e agendas que não fazem parte das crenças e práticas fundadoras dos grupos, o poder público espetaculariza a cultura popular, muitas vezes com a intenção de justificar sua própria existência, ainda que isso possa se reverter em ajuda financeira aos grupos. 
A rigor, também é importante ter cuidado com isso, pois se as novas gerações de Penitentes, ou de qualquer grupo, se acostumam a sempre receber dinheiro quando aparecem, pode ser que um dia eles não mais apareçam se não houver um cachê envolvido.

Em relação ao clero, é preciso destacar que essas festas mencionadas são populares e religiosas ao mesmo tempo.

Carlos Alberto Tolovi, em seu livro Mito Religião e Política - Padre Cícero e Juazeiro do Norte, ressalta, com muita propriedade, que não é o sagrado que se manifesta para o povo e que este tem a capacidade de produzir sacralidade. (TOLOVI, 2017, p. 114)

Em geral, os conflitos entre o clero e a religiosidade popular estão ligados à incompreensão dessa realidade e à pretensão do monopólio do sagrado de alguns padres.

Em outras palavras, o clero, assim como o poder público, tanto pode ajudar muito quanto atrapalhar tudo. Ele ajuda, não para legitimar ou autorizar as práticas populares, mas para lembrar justamente o caráter religioso da manifestação e com isso ressaltar que há um comportamento litúrgico, moral e ético que é comum a qualquer religião, qualquer que seja a forma como ela é vivenciada. Se isso não é tão importante na questão dos Penitentes, seria muito útil no caso da festa de Santo Antonio.

No caso dos Penitentes, bastaria talvez a simples presença do padre, ainda que como observador interessado (e não como vigia), em momentos como aquele que Anna Christina chamou de Missa laica.

A atenção e reconhecimento do valor dessas práticas pelo clero também ajudaria na aproximação com outros leigos que desconsideram a importância dessas festas, por não perceberem que elas são, de fato, um patrimônio cultural e histórico de suas comunidades, além de serem ainda um ato religioso de outros leigos.

Numa conversa com um grupo de jovens engajados em atividades pastorais, durante uma pausa que fizeram enquanto arrumavam a igreja para as celebrações da Semana Santa, pude notar opiniões que simultaneamente convergiam e divergiam. 
Eles conheciam mais sobre a festa de Santo Antonio, porque, de fato ela movimenta todos os setores da cidade, mas, de um modo geral, fazem uma distinção ${ }^{10}$ entre o que é religioso e o que não é. Em alguns momentos se identificam como sendo da Igreja, numa outra distinção entre os que consideram que não são e vêm na festa uma oportunidade de conversões desses outros. Refletem sobre as histórias de pessoas mais velhas que falam da maior presença, na festa, de grupos como as Bandas Cabaçais. ${ }^{11}$ Sobre os Penitentes, conhecem pouco mas houve quem se lembrasse da participação de um grupo nas exéquias de um padre, o que parece indicar eventuais e possíveis aproximações desses grupos com o clero. Favoráveis ao incentivo dessa religiosidade popular, para que os grupos continuem existindo, entendem entretanto, que a função deles é eclesial, fomentando a participação do povo nas celebrações litúrgicas.

\footnotetext{
10 Uma distinção que é deles.

11 Semelhante às bandas de pífanos (flautas)
} 


\section{Comentários finais}

O Nordeste e, particularmente o Ceará, tem uma história que é ao mesmo tempo bonita e triste. Estado que é frequentemente vítima de secas infernais, teve campos de concentração, sofreu com as consequências do cangaço, do coronelismo e foi colonizado por missionários que incentivavam o pensamento conformista de que o sofrimento era a vontade de Deus.

Todavia também gerou ícones de uma vigorosa cultura de resistência, especialmente no século XIX. Pe. Ibiapina, Pe. Cícero, Antonio Conselheiro, Zé Lourenço, foram nomes de gente que se dispôs a enfrentar o sofrimento e a usa-lo como alimento para sonhar com outra realidade, pautada na solidariedade.

Os Penitentes são fruto dessa forma de entender a vida. Seu propósito não é uma salvação individual, mas uma mortificação em prol da humanidade, seguindo o modelo do Cristo, que morreu por ela.

Partem de uma concepção de que entre o pecado e o perdão precisa haver uma penitência, um castigo, e houve épocas que levavam isso ao extremo. A rigor, isso continua sendo parte da pregação da Igreja Católica da qual os Penitentes se orgulham de pertencer à sua maneira. Entre o arrependimento e o perdão sempre houve as orações de penitência.

Como eles se dispõe a viver uma vida de santidade, seu sacrifício é também pelos outros, para que também sejam santos. É como se buscassem concentrar em si a remissão dos pecados do mundo, como fez o Cristo, e fazem disso uma missão que dá enorme significado a suas vidas. Saber de cor os Benditos é motivo de orgulho e sinal de dedicação. Quanto mais Benditos se sabe, melhor.

É a religião, não apenas como ópio mas, definitivamente, como o suspiro daqueles que, sendo do povo, reagem aos desafios e buscam a salvação do povo. 


\section{BIBLIOGR AFIA}

CARVALHO, Anna Christina Farias de. Sob o signo da fé e da mística. Fortaleza: Editora IMEPH, 2011.

COMBLIM, José. Pe. Ibiapina. São Paulo: Paulus, 2012.

HILL, Jonathan. A história do Cristianismo. São Paulo: Edições Rosari, 2009.

ROUILLARD, Philippe. A História da Penitência - das origens aos nossos dias. São Paulo: Paulus, 1999.

TOLOVI, Carlos Alberto. Mito, Religião e Política - Padre Cícero e Juazeiro do Norte. Curitiba: Editora Prisma, 2017. 


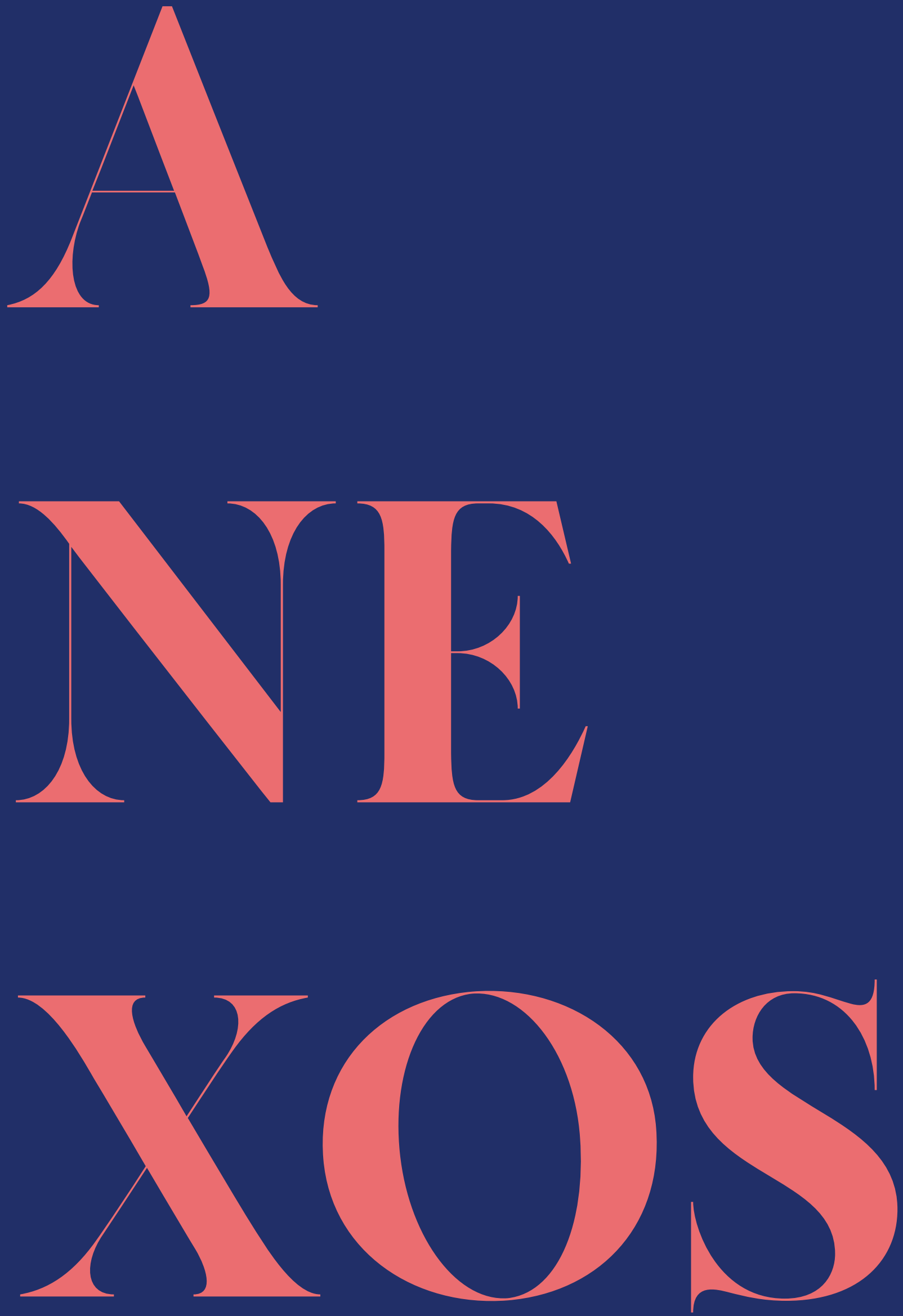
O Município de Melgaço, na pessoa do seu Presidente, Manoel Batista Calçada, reconhece o mérito, a qualidade e a relevância do trabalho de investigação e inventariação dos fornos comunitários de Castro Laboreiro e Lamas de Mouro, para o município de Melgaço, no sentido da sua salvaguarda e divulgação, e agradece a Diana Alexandra Simões Carvalho por este projecto da sua iniciativa e que levou a bom porto entre 2014 e 2017.

Melgaço, 28 de maio de 2019

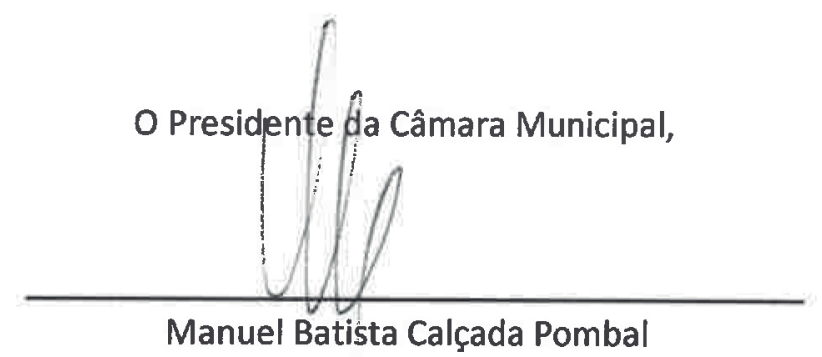

